\title{
Sleep quality among patients with chronic obstructive pulmonary disease at a university hospital in Egypt \\ Clinic
}

Abstract

Background: Disturbed sleep is a common complaint in patients with the Chronic Obstructive pulmonary Disease (COPD). Moreover, the factors affecting sleep quality of those patients remain unclear.

The aim of this study: was to assess sleep quality among patients with the chronic obstructive pulmonary disease.

Material and Methods: A descriptive exploratory design was utilized and conducted at the intermediate respiratory care unit at Mansoura university hospital including a convenient sample of 60 patients of both sexes, able to verbalize their health status and who stayed more than two days at intermediate care unit.Patients' Demographic, Health Relevant Data, Pittsburgh Sleep Quality Index and factors affecting sleep quality instruments were utilized in data collection.

Results: Most of the patients were married males, their age ranged between 50 and 69 years with a mean age of 61 and one-third of them were smokers. The majority of patients (80\%) had the unsatisfactory level of sleep according to Pittsburgh Sleep Quality Index. The factors altered the patients' sleep included physiological factors such as the production of sputum and chest tightness. The most influential environmental factors included the movement of health care members, performing nursing procedures and administration of nebulizer sessions. The dietary factors included hunger. The influential psychological factors included patients' anxiety and fear of being alone. Finally, daily life habits as daytime naps and smoking.

Conclusion and recommendations: It can be concluded that most of the patients had an unsatisfactory level of sleep and need to be improved. As well, further researches are highly recommended on a larger probability sample in different geographical hospitals in Egypt to ensure generalization of findings.

\section{Keywords: Sleep quality,chronic obstructive pulmonary disease}

\section{Introduction}

COPD is a common respiratory disorder. Its prevalence in Egypt was valued to be about 10\% (Said AF,et al) [1]. Furthermore, about a quarter of adults worldwide have COPD and half of them suffer from the difficulty of falling or remaining asleep or altered sleep that affects their activity during daytime (Kapella MC et al.) [2]. The COPD burden is increasing worldwide and its physical, economic and mortality costs are massive and more than 65 million people are affected by moderate to severe COPD (Fraser JF et al) [3]. Disturbed sleep has been found to be associated with more severe disease, frequent exacerbations, and increased mortality (Nunes DM et al. \& Sharafkhaneh A et al) [4,5]. Poor quality of sleep in patients with COPD has been revealed to be due to frequent desaturation particularly during rapid eye movement sleep that exacerbates their sleep disruption. As well, COPD patients often suffer from lack of sleep due to a productive cough and chronic dyspnea (Shaarawy H, et al \& Soler X, et al) $[6,7]$. Unsatisfactory level of sleep has been revealed by at least $40 \%$ of COPD patients that can influence their recovery and quality of life. It is significant to enhance management of the respiratory diseases to lessen the impression on night-time sleep though, COPD patients should be assessed for simultaneous sleep problems(Tsai SC) [8].

There are few studies researched in Egyptian contexts exploring the sleep quality pattern among chronic obstructive pulmonary disease patients. With this background, the current study was conducted to investigate
Nahla shaaban Khalil ${ }^{1 *}$, Marwa Fathallah Mostafa², Nagwa Yehya Ahmed ${ }^{3}$ and Ahmad yuones El-sayedd ${ }^{2 *}$

${ }^{1}$ Critical care Nursing, Faculty of nursing Cairo University ${ }^{2,3}$ Critical care Nursing, Faculty of nursing, Mansoura University. ${ }^{4}$ Faculty of Medicine - Mansoura University.

*Author for correspondence:

nahlakhali128@yahoo.com 
the factors affecting sleep quality among patients with chronic obstructive pulmonary disease at intermediate respiratory care unit at a governmental hospital. The study was aimed to assess factors affecting sleep quality among patients with COPD at intermediate respiratory care unit.

\section{Subjects and Methods}

A descriptive exploratory research design was utilized consisting of a convenient sample of 60 COPD patients at intermediate respiratory care unit (IRCU) at Mansoura University Hospital. The inclusion criteria included patients' age more than 35 years old, able to verbalize their health status and stay more than two days at intermediate care unit. The exclusion criteria included the patients who had an altered level of consciousness or had any psychiatric disorders were excluded from the study.

Later, an official permission was obtained from the ethics committee of the faculty of Nursing, Mansoura University as well as the hospital administrator to initiate data collection from assigned patients. Next, the patients were interviewed and were reported that participation in this study was voluntary and written consents were taken from those patients. During which the Patients' demographic, health relevant data, Pittsburgh Sleep Quality Index and factors affecting sleep quality instruments were utilized in data collection.

Pittsburgh Sleep Quality Index (PSQI) is a self-reported questionnaire that including 19 questions that summate seven "sub items" scores (sleep quality, sleep latency, sleep duration, habitual sleep efficiency, sleep disturbances, use of sleeping medication, and daytime dysfunction (Buysse D, et al ) [9]. Each item score is ranged from 0-3 points. The total PSQI score is 21.If the total PSQI score is $\leq 5$, it indicates a satisfactory level of sleep. If the total PSQI score is $>5$, it points to an unsatisfactory level of sleep. Quality of Sleep Index adopted from Abou Elatta, SG [10] was used to assess factors affecting the sleep quality. It consists of 6 items distributed as follows: physiological changes in COPD patients during sleep, environmental factors affecting sleep, meals, psychiatric status, daily life habits and finally, factors promoting sleep. The scores of Quality of Sleep Index ranged from 0 to 4 . Factor's total score of 0-2 indicates that it doesn't affect the quality of sleep and factor's total score of 3-4 indicates that it affect the quality of sleep. The reliability of both tools was calculated using Cronbach's alpha test. The values were 0.879 for PSQI and 0.739 for Quality of Sleep Index.Statistical package of social sciences (SPSS) version 16.0 (SPSS Inc., Chicago, IL, USA) was used for statistical analyses. Parametric data were expressed in mean \pm standard deviation. One sample K-S test and Pearson Chi-square test were utilized.

\section{Results}

\section{Patients' base line characteristics}

As can be seen from the (TABLE 1) that most of the patients, their age ranged between 50 and 69 years with the mean age $61.5 \pm$ 6.47. Two-thirds of patients $(60 \%)$ were male and almost half of them (48.3\%) were retired. Regarding marital status, two-thirds of them were married (63.3\%).Concerning the patients' education and income, almost half of patients (45\%) were secondary diploma graduates and more than two-thirds of patients $(65 \%)$, their income is inadequate. Finally, nearly one-third of the patients were smokers (36.7\%).

The quality of sleep in patients with COPD. FIGURE 1clarifies that majority $(80 \%)$ of the studied subjects had an unsatisfactory level of sleep according to PSQI.

\begin{tabular}{|c|c|c|c|}
\hline \multicolumn{2}{|c|}{ Variables } & $\mathbf{N}$ & $\%$ \\
\hline \multirow{3}{*}{ Age } & $50-59$ & 26 & 43.3 \\
\hline & $60-69$ & 25 & 41.6 \\
\hline & $\geq 70$ & 9 & 15.0 \\
\hline \multicolumn{4}{|c|}{ Mean \pm SD $61.5833 \pm 6.47627$} \\
\hline \multirow{2}{*}{ Sex } & Male & 36 & 60.0 \\
\hline & Female & 24 & 40.0 \\
\hline \multirow{3}{*}{ Occupation } & Employed & 6 & 10.0 \\
\hline & Unemployed & 25 & 41.7 \\
\hline & Retired & 29 & 48.3 \\
\hline \multirow{2}{*}{ Marital status } & Married & 38 & 63.3 \\
\hline & Widow & 22 & 36.7 \\
\hline \multirow{5}{*}{ Education } & Illiterate & 24 & 40.0 \\
\hline & Read and write & 1 & 1.7 \\
\hline & Primary education & 5 & 8.3 \\
\hline & University education & 3 & 5.0 \\
\hline & Secondary diploma & 27 & 45.0 \\
\hline \multirow{2}{*}{ Income } & Adequate & 21 & 35.0 \\
\hline & Inadequate & 39 & 65.0 \\
\hline \multirow{2}{*}{ Smoking } & Yes & 22 & 36.7 \\
\hline & No & 38 & 63.3 \\
\hline
\end{tabular}




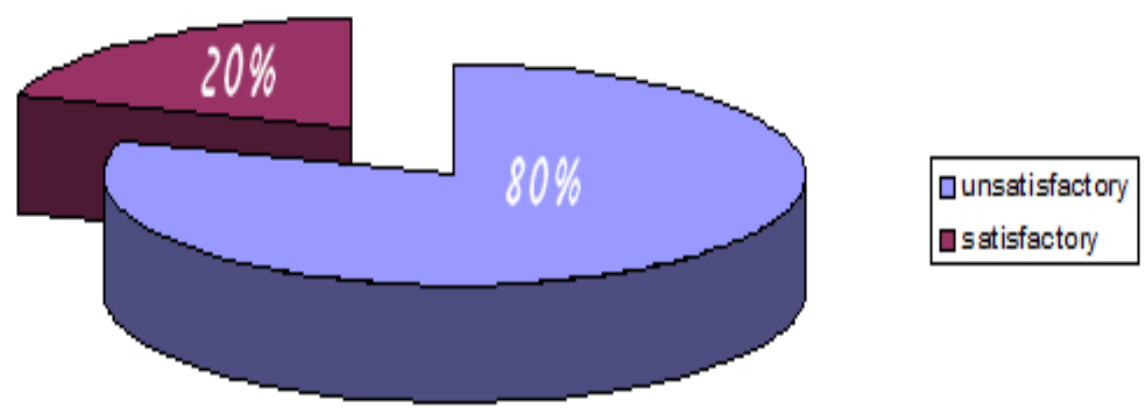

FIGURE 1: Percentage distribution of the patient's quality of sleep according to PSQI.

\section{- Factors affecting sleep quality at IRCU}

TABLE 2 illustrates that about two-thirds of the COPD patients were affected during their sleep by physiological factors including shortness of breath, production of sputum and chest tightness (61.7\%, 70\%, and $63.3 \%$ respectively). In relation to environmental factors, about three fourths $(76.7 \%)$ of the patients were influenced by performing nursing procedures during their sleep, while more than two thirds $(66.7 \%)$ were affected by the movement of health care members during their work. Moreover, noise affected the sleep of about two thirds (65\%) of them. At the same time, light disturbed the sleep quality of half $(51.7 \%)$ of those patients.

Similarly, it can be seen also from TABLE 2 that the heavy meals and hunger disturbed the sleep quality of more than half of studied patients $(56.7 \%$ and $66.7 \%$ respectively). Regarding psychological status, anxiety, fear of death and fear of being alone interrupted the sleep quality of the majority of studied patients (71.7\%, 61.6\%,and 75\% respectively). Also, the sleep of two thirds $(61.7 \%)$ of the studied patients was disturbed by daytime naps while smoking affected sleep quality of one third (36.7\%) of them. Concerning factors promoting sleep, the diet included milk and its products as well as, keeping on spiritual status as listening to Quran/Gospel had improved effect on sleep in about one-third of the studied patients (35\% and $38.3 \%$ respectively).

TABLE 3 clarifies that there was a strong statistically significant positive correlation between PSQI and the physiological factors including shortness of breath, production of sputum and chest tightness, the environmental factors as noise, light, movement of health care members, nursing procedures and nebulizer sessions, meals including heavy meals and hunger, psychological status as anxiety, fear of death and fear of being alone, daily life habits as daytime naps and smoking. On the other hand, a strong statistically significant negative correlation was found between PSQI and both spiritual status as listening to Quran/Gospel and diet that promote sleep as milk and its products $(\mathrm{r}=-0.69 ; \mathrm{p}=0.00$ and $\mathrm{r}=-0.73 ; \mathrm{p}=0.00$ respectively) (TABLE 4).

\section{Discussion}

The analysis of data in the current study revealed that the majority of study patients had an unsatisfactory level of sleep. The researchers interpreted the reasons for patients' poor sleep to that COPD patients experience nocturnal symptoms including dyspnea, wheezing and productive cough that have a negative impact on sleep quality and health status. As well, the presence of symptoms all over the day was associated with worse sleep quality (Di Marco F,et al.,Miravitlles M, et al \&Stephenson ) [11-13]. Our study finding is agreed with a similar study done by Sharma K, et al.[14] who examined the quality of sleep and quality of life among COPD patients and found that more than two-thirds of the patients had poor sleep quality. Similarly, Zohal MA, et al.[15] revealed that nearly threefourths of the patients had poor sleep quality. Furthermore, this finding is in harmony with Chang $\mathrm{CH}$, et al.[16] who revealed that more than half of the patients had poor sleep quality and on the same line was Dignani L, et al. [17] who studied sleep and quality of life in people with COPD; found that the majority of the patients had poor sleep quality. On the contrary, this finding is contradicted with Geiger Brown J, et al.[18] who studied sleep quality and acute exacerbations of COPD found that less than half of the patients had poor sleep quality.

Regarding factors affecting sleep quality, the present study findings revealed that about twothirds of the COPD patients affected by shortness of breath during sleep. This finding agreed with Chang $\mathrm{CH}$, et al.[16] who found that the most common cause of sleep disturbance was being unable to breathe comfortably. Moreover, this finding corresponds with Mocarski $\mathrm{M}$, et al. [19] who assessed the psychometric properties of the night-time symptoms of COPD, revealed that most of the patients experienced shortness 
TABLE 2: Frequency distribution of the factors affecting sleep quality among patients with COPD $(n=60)$.

\begin{tabular}{|l|c|c|}
\hline \multicolumn{1}{|c|}{ Variables } & N & $\%$ \\
\hline physiological factors & 37 & 61.7 \\
\hline - Shortness of breath & 42 & 70.0 \\
\hline - Production of sputum & 38 & 63.3 \\
\hline - Chest tightness & \multicolumn{2}{|c|}{} \\
\hline
\end{tabular}

\section{Environmental Factors}

\begin{tabular}{|l|l|l|}
\hline - Light & 31 & 51.7 \\
\hline - Noise & 39 & 65.0 \\
\hline - Movement of health care members & 40 & 66.7 \\
\hline - Nursing procedures & 46 & 76.7 \\
\hline - Nebulizer Sessions & 26 & 43.3 \\
\hline Meals & \multicolumn{2}{|l}{} \\
\hline
\end{tabular}

\section{Meals}

\begin{tabular}{|l|c|c|}
\hline - Heavy meals & 34 & 56.7 \\
\hline - Hunger & 40 & 66.7 \\
\hline
\end{tabular}

\section{Psychological Status}

\begin{tabular}{|l|c|c|}
\hline - Anxiety & 43 & 71.7 \\
\hline - Fear of death & 37 & 61.6 \\
\hline - Fear of being alone & 45 & 75.0 \\
\hline Daily Life Habits & & \\
\hline - Daytime naps & 37 & 61.7 \\
\hline - Smoking & 22 & 36.7 \\
\hline
\end{tabular}

\section{Factors Promoting Sleep}

\begin{tabular}{l|l|l|}
\hline - Spiritual status as listening to Quran/ Gospel & 21 & 35.0
\end{tabular}

- Diet that promote sleep as milk and its $23 \quad 38.3$ products.

\begin{tabular}{|c|c|c|c|c|}
\hline Variables & Mean & SD & $\begin{array}{c}\mathbf{R} \\
\text { value }\end{array}$ & $\begin{array}{c}P \\
\text { value }\end{array}$ \\
\hline Age & 61.5833 & 6.47627 & \multirow{2}{*}{0.33} & \multirow{2}{*}{0.01} \\
\hline PSQI & 12.3333 & 5.09126 & & \\
\hline
\end{tabular}

of breath at night-time and altered their sleep. This result might be attributed to an obstruction in the airways secondary to their narrowing bronchioles lead to limitation of the flow of air to and from the patients' lungs, causing shortness of breath (Kanwade A, et al) [20].

Concerning the production of sputum, the present study revealed that the sleep quality of more than two-thirds of the COPD patients was affected by it. This finding corresponds with Hartman JE, et al [21] who investigated the association between frequent sputum production and disturbed night's rest and impaired sleep quality in COPD patients. They reported that one-third of the patients who reported frequent sputum production during daytime had more disturbances during night's rest and also worse sleep quality. In addition, about two-thirds of the COPD patients in the
TABLE 4: Correlation between PSQI and factors affecting sleep quality among patients with COPD ( $n=60)$.

\begin{tabular}{|c|c|c|c|c|c|}
\hline \multirow{2}{*}{ Variables } & \multirow{2}{*}{$\begin{array}{l}\text { Referenced } \\
\text { limit }\end{array}$} & \multicolumn{4}{|c|}{ PSQI } \\
\hline & & M & SD & $R$ value & P value \\
\hline \multicolumn{6}{|l|}{ Physiological factors } \\
\hline Shortness of breath & $0-4$ & 2.6500 & 1.13234 & 0.71 & 0.00 \\
\hline Production of sputum & $0-4$ & 2.8833 & 0.78312 & 0.76 & 0.00 \\
\hline Chest tightness & $0-4$ & 2.8000 & 0.98806 & 0.72 & 0.00 \\
\hline \multicolumn{6}{|l|}{ Environmental factors } \\
\hline Light & $0-4$ & 2.3333 & 1.69412 & 0.65 & 0.00 \\
\hline Noise & $0-4$ & 2.8833 & 1.24997 & 0.62 & 0.00 \\
\hline Movement of health care members & $0-4$ & 2.8833 & 1.20861 & 0.68 & 0.00 \\
\hline Nursing procedures & $0-4$ & 3.3167 & 0.96536 & 0.71 & 0.00 \\
\hline Nebulizer Sessions & $0-4$ & 2.0000 & 1.46137 & 0.58 & 0.00 \\
\hline \multicolumn{6}{|l|}{ Meals } \\
\hline Heavy meals & $0-4$ & 2.3167 & 1.26881 & 0.64 & 0.00 \\
\hline Hunger & $0-4$ & 2.7500 & 1.18786 & 0.64 & 0.00 \\
\hline \multicolumn{6}{|l|}{ Psychological status } \\
\hline Anxiety & $0-4$ & 2.9333 & 1.42456 & 0.82 & 0.00 \\
\hline Fear of death & $0-4$ & 3.0667 & 1.00620 & 0.63 & 0.00 \\
\hline Fear of being alone & $0-4$ & 3.1667 & 1.01124 & 0.74 & 0.00 \\
\hline \multicolumn{6}{|l|}{ Daily life habits } \\
\hline Daytime naps & $0-4$ & 2.6667 & 0.98577 & 0.71 & 0.00 \\
\hline Smoking & $0-4$ & 1.4667 & 1.87279 & 0.36 & 0.004 \\
\hline \multicolumn{6}{|l|}{ Factors promoting sleep } \\
\hline Spiritual status as listening to Quran/ & $0-4$ & 2.2167 & 0.99305 & -0.69 & 0.00 \\
\hline $\begin{array}{l}\text { Diet promote sleep as milk and its } \\
\text { products }\end{array}$ & $0-4$ & 2.3333 & 1.23050 & -0.73 & 0.00 \\
\hline
\end{tabular}

current affected by chest tightness during sleep. This finding is congruent with Mocarski $\mathrm{M}$, et al [19] who reported that a large percent of the patients with COPD experienced chest tightness at nighttime and caused sleep disturbance.

Performing nursing procedures during the patients' sleep were one of the main causes of sleep disturbance that affected most of the patients and reflected their quality of sleep. This finding was in the same line with Yilmaz M, et al.[22] who assessed sleep quality of hospitalized patients reported that the treatment and care given during sleep time affected the sleep quality of the patients. Similarly,Stewart JA, et al.[23] who studied factors affecting sleep quality in ICU found that the patients had been awakening for procedures. This finding could be due to that many required assessments are scheduled on an hourly basis as vital signs monitoring, fluid balance assessments, and pharmacological administration. These procedures in combination with basic care create an environment where sleep is disturbed (Delaney LJ) [24].

The other main environmental factor was the movement of health care members during 
their work affected about two-thirds of the patients' sleep. This might be due to that ICUs is considered a complex auditory environment that makes noise such as ECG monitor alarms, mechanical ventilation, transport equipment, telephones, conversations between nursing and medical staffs, nursing activities and even the footsteps of the staff results in circadian disruption and sleep abnormalities (Korompeli A, et al) [25]. Another main environmental factor that affected COPD patients' sleep is noise that influenced about two-thirds of the studied patients. On the same line, were Stewart JA, who studied control and sleep perception in hospitalized elder adults and who studied hospital noise and patients' wellbeing as they showed that patients are unable to sleep or comfort due to hospital noise (Adachi M, et al \& Cunha M ) [26,27]. This might be due to patients exposed to simulated ICU sounds had a decreased REM sleep and experienced prolonged sleep latency, increased number of arousals and poorer sleep quality (Knauert MP, et al ) [28].p There is a great need to reduce disturbing and unexpected sounds and noises around critically ill patients to facilitate wellbeing, sleep, and recovery. The shifts between silence and disturbing sounds make stress and later delusional memories of the ICU patients (Pulak LM, et al) [29].

On the same line, nearly half of the patients were affected by nebulizer sessions. This might be due to that nebulizer sessions produce loud sound and when patients are exposed to this sound during their sleep, they assume a more superficial stage of the sleep cycle. Constant disturbances cause a difficulty for the patients to enter deep sleep and REM sleep, as these stages are sensitive to noise (White BL, et al) [30] On the other hand, our finding is incongruent withBudhiraja $\mathrm{R}$, et al. who assessed insomnia among COPD patients, reported that there is no adverse influence of any inhalers on sleep (Budhiraja R, et al) [31].

Light is another factor that causes sleep disturbance among COPD patients, our current study revealed that light disturbs the sleep of about half of patients. In the same line was Korompeli A, et al. who had a study about the circadian disruption of ICU patients, clarified that most patients reported that sleep in ICU is inferior to that experienced at home and light is one of the most five frequently cited reasons for sleep deprivation. Furthermore, this finding is congruent with Stewart JA, et al. who reported that light levels were a barrier to sleep in the ICU $[23,25]$.

Regarding the psychological factors that affect sleep quality, the results of the present study revealed that anxiety and fear of being alone interrupt sleep of the majority of studied patients. This finding agreed with Zhang L, et al. who reported that missing the patients' relatives and the worry is an important factor affecting sleep quality.Moreover, this finding is consistent with Ding $Q$, et al. who evaluated factors influencing patients' sleep in ICU, reported that more than half of the patients expressed that worry affected their sleep negatively $[32,33]$.

The present study revealed that sleep quality of the majority of the studied patients had been disturbed by daytime snaps. This is inconsistent with Vukoja M, et al. who reported that only $8 \%$ of the COPD patients have daytime snaps. This may be explained in the light of Dunn $\mathrm{H}$, et al that daytime sleeping is evidence to the loss of normal sleep cycles with a circadian rhythm and napping is considered a causative issue in phase-shifting circadian rhythms and may lead to earlier awakening [34.35].

It is obvious from the current study that patients who had poor sleep quality were smokers. This finding is in the same line with Costa $M$, et al $\{36\}$.that evaluated the relation between cigarette smokings and sleep disturbance and found that smokers have less total sleep time. This might be due to tobacco smoking amongCOPD patients is known to increase respiratory symptoms, deteriorate lung function as forced expiratory volume in one second (FEV1) is declined and raise exacerbation rates (Vozoris N, et al) \{37\}. Moreover, Tan E, et al. realized that smokers have a greater decline in forced expiratory volume in one second (FEV1) than non-smokers [38].

Concerning factors promoting sleep, the diet as milk and its products had a good effect on sleep quality in about one-third of the studied patients. This finding may be attributed to milk is an essential drink as it provides high-quality protein. Proteins in milk influence sleep through tryptophan which is a precursor for serotonin in the brain. Serotonin is a neurotransmitter that acts as a sleep-inducing agent as it enhances melatonin synthesis which is responsible for 
sleep and wake process regulation (Misra $S$, et al \& Singh R, et al) $[39,40]$.

The current study showed that keeping on spiritual status as listening to Quran/Gospel had a good quality of sleep in one-third of the studied patients. This may be due to that listening to the Quran/Gospel helped in depression and stress relief. Moreover, the Quran/Gospel listening intervention reduces patients' physiological stress response that is, in turn, will help in falling asleep (Chlan L, et al.,Hunter B , et al \& Kandeel N, et al) [41-43].

In the current study, there was a statistically significant positive correlation between PSQI and age. Such study finding may be explained by that sleep disturbance in COPD patients can arise from age-related changes as it causes reductions in homeostatic sleep pressure and arousal threshold.Further, the older adults take a long time to fall asleep which disturbs sleep (Lee-Chiong T\& Park M, et al) [44,45]. Moreover, the level of melatonin decreases when the age increases and melatonin is responsible for regulating sleep and wake process (Singh $\mathrm{R}$, et al) [40]. This finding is in agreement with the study of Park MJ, et al. $\{45\}$ who made a study about factors affecting the subjective sleep quality of hospitalized elderly patients and revealed that there was a significant low sleep quality in the elderly patients. In contrast were Geiger Brown J, et al.who emphasized that there was a statistically significant negative correlation between PSQI and age [18].

Analysis of the study data revealed that there was a statistically significant positive association between PSQI and shortness of breath. On the contrary was Soler X, et al. [7] who studied the impact of pulmonary rehabilitation on sleep quality in COPD, reported that PSQI was negatively correlated with shortness of breath. Moreover, there was a strong statistically significant positive association between PSQI and production of sputum. This finding is in the same line with Chang $\mathrm{CH}$, et al. \& Hartman, $\mathrm{J}$ E, et al who stated that frequent sputum production had a significantly worse sleep quality score [16,21].

There was a positive statistically significant relation between PSQI and the environmental factors including nursing procedures, the movement of health care members during their work, noise and light, nebulizer sessions.
This finding goes hand in hand with Huang $\mathrm{HW}$, et al.who evaluated the impact of oral melatonin and wearing earplugs and eye masks on nocturnal sleep in an intensive care unit environment stated that patients reported worse subjective sleep quality due to ICU noise and light. Moreover, the same finding reported by Ritmala CM, et al. who assessed the effect of nursing care activities on sleep in ICU, found that there was an increase in the amount of light, so the number of care activities increased and may have adverse effects on sleep [46, 47].

Furthermore, the current study illustrated a positive statistically significant correlation between PSQI and daytime naps. This finding was contradicted with Vukoja $M$, et al.who found that sleep quality is not significantly related to daytime sleepiness. It is also noted that there was a positive statistically significant relation between PSQI and smoking [34]. The same result was reported in another study by Alt JA, et al. who carried out a study about the assessment of sleep quality and disease severity among chronic rhinosinusitis patients, they reported that significantly worse sleep was found in patients who were tobacco smokers [48]. This result may be related to that cigarette smoking promotes deposition of particles in the lower airways that has an effect on the respiratory defences including mucociliary clearance and also, small amounts of cigarette smoke can result in lung functions reduction which will affect the patients' quality of sleep (Hasan $\mathrm{SH}$, et al) [49].

\section{Conclusion}

It can be concluded that Poor sleep quality is common in patients with COPD as it occurs in $80 \%$ of the studied patients mainly due to physiological changes such as the production of sputum and chest tightness, environmental factors included movement of health care members and performing nursing procedures. The dietary factors included patients' hunger. Moreover, the influential psychological factors contained patients' anxiety and fear of being alone. The patients' daily life habits that affect their sleep negatively were daytime naps and smoking.

\section{Recommendations}

According to the findings of the current study, the following recommendations were suggested: 
- Comprehensive simple Arabic booklet that includes instructions to improve sleep quality

- Provide allowed drinks like milk and natural herbs to improve the quality of sleep among COPD patients
- Control ICU environmental stressors that affect sleep quality such as light, noise, movement of health care members during their work, nursing procedures and nebulizer sessions 


\section{References}

Said AF, Ewis, AA, Omran AA, Magdy ME, Saleeb MF. Prevalence and predictors of chronic obstructive pulmonary disease among high-risk Egyptians. Egyp. J. Bronchol.9(1), 27-33 (2015).

Kapella MC, Herdegen JJ, Laghi F, Steffen AD, Carley DW. Efficacy and mechanisms of behavioral therapy components for insomnia coexisting with chronic obstructive pulmonary disease: Study protocol for a randomized controlled trial. Trials. 17(1), 258 (2016).

Fraser JF, Spooner AJ, Dunster KR, Anstey CM,Corley A. Nasal high flow oxygentherapy in patients with COPD reducesthe respiratory rate and tissue carbondioxidewhileincreasing tidal and end-expiratory lung volumes: a randomized crossover trial. Thorax. 71(8), 759-761 (2016).

Nunes DM, Mota RM, de Pontes Neto OL, Pereira ED, de Bruin VM, de Bruin PF. Impaired sleep reduces the quality of life in chronic obstructive pulmonary disease. Lung. 187(3), 159163 (2009).

Sharafkhaneh A, Jayaraman G, Kaleekal T, Sharafkhaneh H, Hirshkowitz M. Sleep disorders and their management in patients with COPD. Ther. Adv. Respir. Dis.3(6) 309-318 (2009).

Shaarawy H, ElhawaryA. Study of sleep-relatedrespiratorydisorders in patients with idiopathic pulmonary arterial hypertension. Egypt. J. Chest Dis. Tuberc. 65(1), 233-237 (2016).

Soler X, Diaz PC, RiesAL. Pulmonary rehabilitation improves sleep quality in chronic lung disease. COPD.10(2), 156163 (2013).

Tsai SC. Chronic obstructive pulmonarydisease and sleeprelateddisorders. Curr. Opin. Pulm. Med.23(2), 124-128 (2017).

Buysse DJ, Reynolds CF, Monk TH, Berman SR, Kupfer DJ. The Pittsburgh sleep quality index: A new instrument for psychiatric practice and research. Psychiatry Res. 28(2) 193-213 (1989).

Abou ElattasG. Factors affecting sleep disturbance and quality of life for patients undergoinghemodialysisat Mansoura universityhospitals (Master'sthesis, Mansoura University) (2015).

Di Marco F, Santus P, Scichilone $\mathrm{N}$, et al. Symptom variability and control in COPD: Advantages of dual bronchodilationtherapy. Respir. Med.125, 49-56 (2017).

Miravitlles M, Worth H, CataluñaJJS, et al.Observational study to characterize 24-hour COPD symptoms and theirrelationship with patient-reported outcomes: results from the ASSESS study. RespirRes.15(1), 122 (2014).

Stephenson JJ, Cai Q, Mocarski M, Tan H, Doshi JA,Sullivan SD. Impact and factorsassociatedwithnighttime and early morning symptoms among patients with chronic obstructive pulmonary disease. Int. J. Chron. Obstruct. Pulmon. Dis. 10, 577 (2015).

Sharma K, Choyal T, Chaturvedi H,Pandey R. Sleep quality and quality of life in patients with COPD. Chest. 150(4), 895A (2016).

Zohal MA, Yazdi Z, Kazemifar AM, Mahjoob P, Ziaeeha M. Sleep quality and quality of life in COPD patients with and withoutsuspected obstructive sleepapnea. SleepDisord. 2014, 4.

Chang $\mathrm{CH}$, Chuang LP, Lin $\mathrm{S}$ $\mathrm{W}$, et al. Factors responsible for poor sleep quality in patients with chronic obstructive pulmonary disease. $B M C$ pulm. Med.16(1), 118 (2016).

Dignani L, Toccaceli A, Lucertini C, Petrucci C,Lancia L. Sleep and quality of life in people with COPD: a descriptivecorrelational study. Clin. Nurs. Res. 25(4), 432-447 (2016).

Geiger Brown J, Lindberg S, Krachman $S$, et al. Self-reported sleep quality and acute exacerbations of chronic obstructive pulmonary disease. Int. J. Chron. Obstruct. Pulmon. Dis. 10, 389-397 (2015).

Mocarski M, Zaiser E, Trundell D, Make BJ, Hareendran A. Evaluation of the psychometricproperties of the NighttimeSymptoms of COPD Instrument. Int. J. Chron. Obstruct. Pulmon. Dis. 10, 475-480 (2015).
Kanwade A, Bairagi VK. Classification of COPD and normal lungairwaysusingfeature extraction of electromyographicsignals. Journal of King Saud University-Computer and Information Sciences (2017).

Hartman JE, Prinzen J, Van Lummel RC, TenHacken NH. Frequent sputum production is associated with disturbed night's rest and impaired sleep quality in patients with COPD. Sleep Breath.19(4), 1125-1133 (2015).

Yilmaz M, Sayin Y, Gurler H.Sleepquality of hospitalized patients in surgicalunits.Nurs. Forum. 47(3), 183-92 (2012).

Stewart JA, Green C, Stewart J, Tiruvoipati R. Factorsinfluencingthe quality of sleepamong nonmechanicallyventilated patients in the Intensive Care Unit. Aust. Crit. Care.30(2), 85-90 (2017).

Delaney LJ, Haren F, Lopez V. Sleeping on a problem: the impact of sleep disturbance on intensive care patients-a clinical review. Ann. intensive care. 5(1), 3 (2015).

Korompeli A, Muurlink O, Kavrochorianou N, Katsoulas T, Fildissis G, Baltopoulos G. Circadian disruption of ICU patients: A review of pathways, expression, and interventions. J. crit. Care.38, 269-277 (2017).

Adachi M, Staisiunas PG, Knutson KL, Beveridge C, Meltzer DO, Arora VM. Perceived control and sleep in hospitalized older adults: A sound hypothesis?J. Hosp. Med.8(4), 184-190 (2013).

Cunha M,Silva N. Hospital Noise and Patients' Wellbeing. Procedia. Soc. Behav. Sci.171, 246-251 (2015).

Knauert MP, Haspel JA, Pisani MA. Sleep loss and circadian rhythm disruption in the intensive care unit. Clin. Chest Med.36(3), 419-429 (2015).

Pulak LM, Jensen L. Sleep in the intensive care unit: a review. Journal of intensive care medicine, 31(1), 14-23 (2016).

White BL, Zomorodi M. Perceived and actual noise levels in critical care 
units. Intensive Crit. Care Nurs.38, 18-23 (2017).

Budhiraja R, Parthasarathy S, Budhiraja P, Habib MP, Wendel C, Quan, SF. Insomnia in patients with COPD. Sleep, 35(3), 369-375 (2012).

Zhang L, Sha YS, KongQQ, et al. Factors that affect sleep quality: perceptions made by patients in the intensive care unit after thoracic surgery. Support. Care Cancer. 21(8), 2091-2096 (2013).

Ding Q, Redeker NS, Pisani MA, Yaggi HK, Knauert MP. Factors influencing patients' sleep in the intensive care unit: perceptions of patients and clinical staff. Am. J. Crit. Care. 26(4), 278-286 (2017).

Vukoja M, Kopitovic I, Milicic D, Maksimovic O, Pavlovic PZ, Ilic M. Sleep quality and daytime sleepiness in patients with COPD and asthma. Clin. Respir. J. 12(2), 398-403 (2018).

Dunn H, Anderson MA,Hill PD. Nighttimelighting in intensive care units. Crit. Care Nurse.30(3), 31-37 (2010).

Costa M, Esteves M. Cigarette smoking and sleepdisturbance. Arch. Intern. Med. 17(1), 40-48 (2018).

Vozoris NT, Stanbrook MB. Smoking prevalence, behaviors, and cessation amongindividualswith COPD or asthma. Respir. Med.105(3), 477-484 (2011).

Tan E, Boessen R, Fishwick D, et al. Amicrosimulation model for the development and progression of the chronic obstructive pulmonarydisease. Respir. Med.109(12), 1521-1531 (2015).

Misra S, Khor GL, Mitchell P, Haque S, Benton D. A pilot study to determine the short-term effects of milkwithdifferingglycaemicproperties on sleepamongtoddlers: arandomizedcontrolled trial. $B M C$ pediatrics. 15, 79 (2015).

Singh R, RaoPS. "High melatoninmilkMilk withintrinsichealthbenefit. RRJoDST.5(1), 13-14 (2018).

Chlan LL, Engeland WC, Savik K. Does music influence stress in mechanicallyventilated patients? Intensive. Crit. Care Nurs. 29(3), 121-127 (2013).

Hunter BC, Oliva R, Sahler OJZ, Gaisser DA, Salipante DM,Arezina $\mathrm{CH}$. Music therapy as an adjunctive treatment in the management of stress for patients being weaned from mechanical ventilation. J. Music Ther. 47(3), 198-219 (2010).

Kandeel NA, El Hady MM. The Effect of Listening to Qur'an on Physiological Responses of Mechanically Ventilated
Muslim Patients. IOSR JNHS.6(5), 79-87 (2017).

Lee Chiong T. Chronic obstructive pulmonary disease and sleep. Current Respiratory Care Reports. 2(2), 123-129 (2017).

Park MJ, Kim KH. What affects the subjective sleep quality of hospitalized elderly patients? Geriatr. Gerontol. Int. 17(3), 471-479 (2017).

Huang HW, ZhengBL, Jiang L, et al.Effect of oral melatonin and wearing earplugs and eye masks on nocturnal sleep in healthy subjects in a simulated intensive care unit environment: which might be a more promisingstrategy for ICU sleepdeprivation? Crit. Care.19(1), 124 (2015).

Ritmala CM, Virtanen I, Leivo S, Kaukonen KM,Leino KH. Sleep and nursing care activities in an intensive care unit. Nurs. Health Sci. 17(3), 354-361 (2015).

Alt JA, Smith TL, Mace JC,SolerZM. Sleep quality and diseaseseverity in patients withchronicRhinosinusitis. Laryngoscope. 123(10), 2364-2370 (2013).

Hasan SHS, Rakkah NI, Attaur RS. Effect of smoking on respiratory pressures and lung volumes in young adults. Biomedica.29(2), 96-100 (2013). 